\title{
Striatal Dopaminergic Reward Response Relates to Age of First Drunkenness and Feedback Response in At-Risk Youth
}

\author{
Authors: \\ Barbara J. Weiland ${ }^{1,2}$, Robert A. Zucker ${ }^{2}$, Jon-Kar Zubieta ${ }^{2,}$ Mary M. Heitzeg ${ }^{2}$ \\ Institutions: \\ ${ }^{1}$ University of Colorado, Boulder, CO ${ }^{2}$ University of Michigan, Ann Arbor, MI \\ Corresponding Author: \\ Mary M. Heitzeg, Ph.D. \\ Dept. of Psychiatry \\ The University of Michigan \\ 4250 Plymouth Rd \\ Ann Arbor, MI 48109-2700 \\ Fax: 734-232-0267 \\ Email: mheitzeg@umich.edu
}

Financial Support: This work was supported by NIH grants K01 DA031755 to BJW; K01 DA020088 to MMH; T32 AA07477, R01 AA12217, R37 AA07065 to RAZ, R01 DA022520 to JKZ; a Phil F. Jenkins Foundation award to JKZ; and a NARSAD Brain and Behavior Early Investigator Award to BJW. The authors have no conflicts of interest to declare.

Words: 4897

Words in Abstract: 250

Tables: 1

Figures: 4

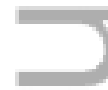

Key Words: Reward, mPFC, NAcc, Dopamine, Impulsivity

This is the author manuscript accepted for publication and has undergone full peer review but has not been through the copyediting, typesetting, pagination and proofreading process, which may lead to differences between this version and the Version of Record. Please cite this article as doi: 


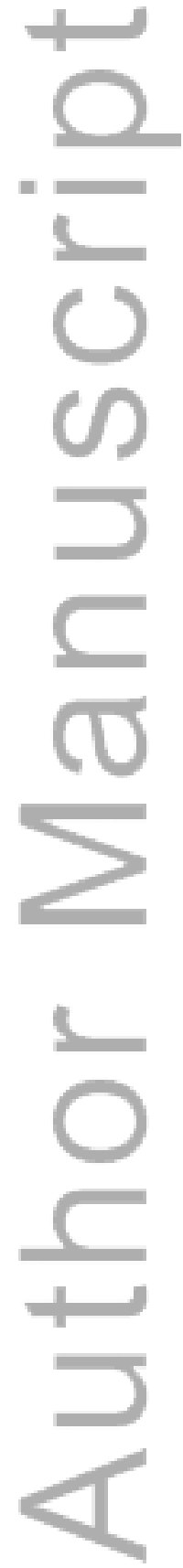




\section{ABSTRACT}

Dopamine receptor concentrations, primarily in the striatum, are hypothesized to contribute to a developmental imbalance between subcortical and prefrontal control systems in emerging adulthood potentially biasing motivation and increasing risky behaviors. Positron emission tomography (PET) studies have found significant reductions in striatal dopamine D2 receptors, and blunted amphetamine-induced dopamine release, in substance users compared to healthy controls. Extant literature is limited and inconsistent concerning vulnerability associated with having a family history of substance abuse (FH+). Some studies have reported familial liability associated with higher dopamine receptor levels, reduced dopamine response to stimulant challenges and decreased response to oral alcohol. However other reports have failed to find group differences based on family history. We explored the interaction of familial liability and behavioral risk with multi-modal molecular and neural imaging of the dopaminergic system. Forty-four young adult male subjects performed monetary incentive delay tasks during both [ $\left.{ }^{11} \mathrm{C}\right]$ raclopride PET and functional magnetic resonance imaging (fMRI) scans. FH+ subjects were identified as Low $(n=24)$ or High Risk $(n=9)$ based on early initiation of drunkenness. FH+ High Risk subjects exhibited heightened striatal dopamine response to monetary reward but did not differ in neural activations compared with $\mathrm{FH}+$ Low Risk subjects and controls with no familial loading (FH-, $\mathrm{n}=11)$. Across all subjects, a negative relationship was found between dopamine release and age of first drunkenness and a positive relationship with neural response to reward receipt. These results suggest that in at-risk individuals higher dopamine transmission associated with monetary reward may represent a particularly useful neurobiological phenotype.






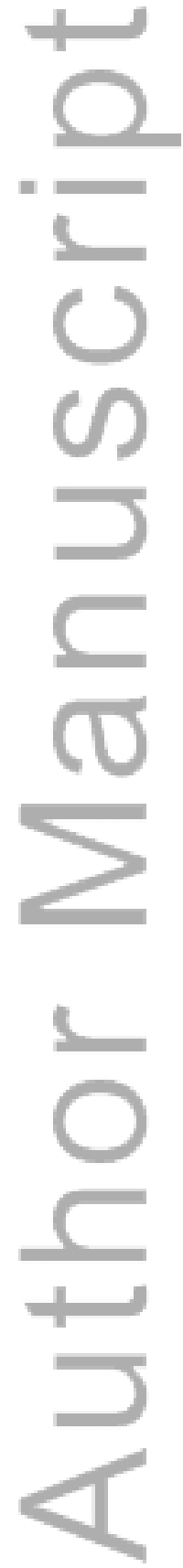


The transition from adolescence to adulthood is a particularly unique developmental period. During these years, heavy substance use, bingeing, and the development of problem substance use generally reaches a peak, and then begins to taper off in most, but not in all, individuals (Johnston et al., 1996). The significant question remains why the majority of youth transition through this period successfully while a $=$ subset remains vulnerable to development of substance use disorders. Concurrent to this period of experimentation, dopamine receptor concentrations, primarily in the striatum (including the nucleus accumbens, NAcc) reach peak levels (Seeman et al., 1987). Critically, the mesolimbic dopamine system is hypothesized to play a role in addiction disorders, with blunted levels of dopamine D2 receptors and dopamine transmission associated with abuse of alcohol as well as stimulants (Trifilieff and Martinez, 2014b). However, it remains unclear whether the dopamine system in some, potentially vulnerable, individuals is different prior to use of substances, or whether this system is altered by use, or both.

\section{A family history of alcohol use disorder (AUD) is a known risk factor for AUD} and other substance use disorders (SUD; National Institute on Alcohol Abuse and Alcoholism, 2000) with genetic influence accounting for $40-60 \%$ of the variance in substance abuse risk (Nestler, 2000). Research has probed the how the dopaminergic system may be involved in familial risk using positron emission tomography (PET). For example, Volkow and colleagues found that non-alcoholic adult members of alcoholic families had higher dopamine D2 receptor availability in the caudate and ventral striatum 
Risk and NAcc Reward Response

than non-alcoholic controls, suggesting high levels of receptors might be a protective factor against alcohol problems in these individuals (Volkow et al., 2006). More recently, Casey et al. (2014) enrolled young adults with a family history of substance use disorders $(\mathrm{FH}+)$ who reported occasional use of psychostimulants. These subjects had blunted stimulant-induced dopamine release compared to two groups of controls - no familial loading (FH-) subjects that were drug-naïve and FH- subjects who matched the high-risk group on personal drug use though the groups did not differ on baseline receptor availability (Casey et al., 2014). Taken together, these studies suggest that for individuals with familial risk, high D2 receptor levels may be associated with resilience while reduced striatal dopamine release following a stimulant challenge might be a biomarker of vulnerability for substance use disorders (Trifilieff and Martinez, 2014a). However, an earlier stimulant challenge study of nonalcoholic subjects found no effect of family history either on D2 receptor levels or dopamine release (Munro et al., 2006). Furthermore, higher dopamine response in response to oral alcohol was recently found to be associated with higher familial loading (Setiawan et al., 2014). Given the contradictions in the literature, additional work is required to understand a link between striatal function and vulnerability.

We sought to further these investigations of risk with an experimental method that behaviorally probes the reward system and has been well-validated during functional magnetic resonance imaging (fMRI), the Monetary Incentive Delay task, (MID, e.g. Knutson et al., 2001). Ventral striatal response to this task, measured by blood oxygen 
level-dependent (BOLD) signal, has been shown to be associated with substance use as well as risk for substance abuse (see recent review by Balodis and Potenza, 2015). For example, work from our laboratory has shown that NAcc anticipatory response to reward is related to drinking behaviors in transitioning at-risk youth (Heitzeg et al., 2014; Yau et al.,2012). In addition, we recently demonstrated that a version of the MID modified for $=$ PET induced the activation of striatal dopamine neurotransmission in healthy individuals (Weiland et al., 2014). Specifically, we found an average 5\% reduction in $\left[{ }^{11} \mathrm{C}\right]$ raclopride binding potential $\left(\mathrm{BP}_{\mathrm{ND}}\right)$ associated with reward . For the current study, we probed neural and molecular substrates of reward processing with the MID during both PET and fMRI scanning of young adults with familial risk and control subjects. In the FH+ sample, we identified as high-risk (HR) those subjects who had reported drunkenness by age 15, a behavioral predictor of later dependence diagnosis (Spak et al., 1997). We sought to explore the interaction between familial and behavioral risk, with multi-modal neuroimaging, hypothesizing that increased NAcc BOLD response and dopamine transmission would be related to both.

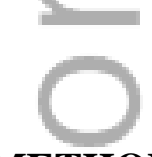

\section{METHODS}

Subjects. Forty-four right-handed, young adult male subjects were recruited from the Michigan Longitudinal Study (MLS), an ongoing prospective community study of families with parental AUD $(\mathrm{FH}+, \mathrm{n}=33)$ and contrast families $(\mathrm{FH}-, \mathrm{n}=11)$ (Zucker et al., 2000). Parental AUD was based on at least one parent meeting DSM-IV AUD criteria 
Risk and NAcc Reward Response

in their lifetime; detailed descriptions regarding the MLS can be found in Zucker et al. (1996). Families in which the mother reported drinking during pregnancy or in which the target child exhibited signs of fetal alcohol syndrome were excluded. Exclusionary criteria were: any neurological, acute, uncorrected, or chronic illness; any current or recent (within six months) treatment with centrally active medications including sedative hypnotics; and history of psychosis or schizophrenia in first-degree relatives. The presence of most Axis I psychiatric or developmental disorders was exclusionary. However, externalizing disorders, including conduct disorder, attention deficit/hyperactivity disorder (ADHD), SUD, were not exclusionary as these may lie on a developmental spectrum with AUD risk. Diagnoses were determined using DSM-IV criteria. Participants were told to abstain from alcohol and other drugs (with the exception of nicotine) for 48 hours prior to their appointment and were given a multidrüg 5-panel urine screen before scanning. Because THC metabolites are detectible in urine for more than 48 hours, we relied on self-report regarding abstinence in the 2 days prior to the study if a participant tested positive for marijuana. Report of marijuana use in the prior 48 hours or a positive screen for other drug use was exclusionary. Subject characteristics are summarized in Table 1 . Protocols were approved by the Investigational Review Board and the Radioactive Drug Research Committee of the University of Michigan and written informed consent was obtained from all subjects. Urine drug screens were performed immediately before both PET and fMRI sessions. 
Substance Use. Substance use was evaluated with the Drinking and Drug History (DDH) Questionnaire (Zucker et al., 1990) which assesses onset of use, quantity, and frequency of alcohol, marijuana and cigarette consumption; any other drug use; and has questions regarding consequences and problems related to alcohol use. This measure was administered yearly since age 11 and used to derive cumulative substance use by calculating annual use and summing these values through the current age. If data was missing for a year, annual use was calculated as an average of the adjacent years. Abuse or dependence diagnoses were assessed using DSM-IV criteria.

Recent Substance Use. The Timeline Follow Back questionnaire (TLFB; Sobell and Sobell, 1992) was used to query daily alcohol, cigarette, and drug use in the 30 days prior to PET scanning. Subjects reported the number of days and quantity (i.e., number of standard drink, cigarettes, joints) of use.

Experimental paradigm - PET. Each subject underwent a single 90-minute PET scan with $\left[{ }^{11} \mathrm{C}\right]$ raclopride, a DA radiotracer with affinity for both D2 and D3 receptors (Seeman et al., 2006) during which they performed a modified version of the MID reward task divided into two conditions, reward and control (Schott et al., 2008). Trials included an incentive cue, indicating the possibility of reward or the absence of a reward, followed by an anticipation delay. A target then appeared for a variable length of time during which subject used a mouse press response in an attempt to gain or avoid losing money; a schematic of the task is presented in Figure 1. In the reward condition, cues varied in amount (from \$0.00-5.00) and valence (win or lose) and a feedback message then 
Risk and NAcc Reward Response

informed subjects of the trial outcome. To increase attention and reduce adaptation to the reward in the reward condition over time during the scan, the feedback included increasing positive sounds (i.e. applause, cash register) due to an increasing reward rate over the task. As a control condition, we utilized a control task involving no incentives, where subjects were instructed to respond to a neutral target and feedback was replaced with a message to continue to the next trial without indication of performance. In both conditions, duration of the response target was calculated based on the individual subject's reaction time during a practice session prior to scanning and dynamically adjusted to a mean hit rate of approximately 66\%. Each presentation lasted for approximately 30 minutes without interruption with the control condition presented first, beginning at 5 minutes after tracer injection, followed by the reward condition, beginning at 45 minutes post-injection. Participants were paid a fixed rate to participate in the study and additionally received any money they won during the reward condition.

PET imaging. PET scans were acquired with a Siemens (Knoxville, TN) HR+ scanner in 3-D mode (reconstructed full-width at half maximum resolution, 5.5 mm in-plane and $5.0 \mathrm{~mm}$ axially). Radiotracer synthesis and image acquisition, coregistration and reconstruction protocols were identical to those used previously (Weiland et al., 2014). Briefly, images were reconstructed, attenuation and motion corrected, and co-registered to each other (Minoshima et al., 1993). Time points were then decay-corrected during data reconstruction. Approximately 15 millicuries (mCi) was administered for each scan ( $<40 \mu \mathrm{g}$ total cold mass for raclopride). Fifty percent of the radiotracer dose was 
Risk and NAcc Reward Response

administered as a bolus with the remainder delivered as a continuous infusion which allows for more rapid equilibration across compartments and is achieved within 5 min of radiotracer administration (Watabe et al., 2000). Twenty-eight image frames were acquired over 90 minutes with an increasing duration (30 seconds up to 10 minutes). PET image processing. Dynamic images were transformed, on a voxel-by-voxel basis, into two coregistered sets of parametric maps: a tracer transport measure ( $\mathrm{K}_{1}$ ratio); and a receptor-related measure at equilibrium $\mathrm{BP}_{\mathrm{ND}}$ (Innis et al., 2007), yielding condition level images obtained from 35-45 min (control) and 60-80 min (reward) after tracer administration, using full equilibrium data, with the cerebellum as the non-displaceable reference region. Under these experimental conditions, reductions in in vivo DA D2/D3 receptor availability $\left(\mathrm{BP}_{\mathrm{ND}}\right)$ are thought to reflect DA release and neurotransmitterreceptor interactions as $\left[{ }^{11} \mathrm{C}\right]$ raclopride binds to D2/D3 receptors in the striatum and is sensitive to endogenous striatal DA release (Zald et al., 2004). With a priori interest in the NAcc (Heitzeg et al., 2014) and given the poor spatial discrimination of PET images (Yoder et al., 2007), 10 mm spherical masks were created centered on the area of peak ventral striatal radioligand displacement, $\mathrm{BP}_{\mathrm{ND}}$, from the 35-45 minute map for each individual (Schott et al., 2008) using the MarsBaR region of interest (ROI) toolbox. For all individuals, the peak $\mathrm{BP}_{\mathrm{ND}}$ lay within $10 \mathrm{~mm}$ masks previously used as ventral striatum $(10,13,-8 ; 11,13,-8$; Weiland et al, 2014). Data from individual control and reward maps were extracted for quantification of regional $\mathrm{BP}_{\mathrm{ND}}$ and calculation of percent change, $\triangle \mathrm{BP}_{\mathrm{ND}}$, for use in statistical analyses. Reductions in $\Delta \mathrm{BP}_{\mathrm{ND}}$ from control 
Risk and NAcc Reward Response

to active conditions reflect activation of DA D2/D3 neurotransmission (Carson et al., 1997). Hereafter we refer to this as incentive/reward-associated DA release although we note that the reward condition included loss trials and, due to the temporal resolution of PET, combines all events (i.e. cue presentation, anticipation, outcome, etc.) into a single metric.

fMRI paradigm. Brain response during anticipation and feedback of incentive stimuli was probed in a fMRI experiment using a version of the MID task similar to that performed in the PET scan, see Figure 1. Each session involved 72 6-second trials consisting of four events. First, subjects were presented with an incentive cue (2000 ms) of seven possible values (gain of $\$ 0.20, \$ 1.00 \$ 5.00$; loss of $\$ 0.20, \$ 1.00 \$ 5.00$; or no change \$0). This was followed by a 2000 ms anticipation delay. Next, a target appeared for a variable length of time (200- $300 \mathrm{~ms}$ ) during which subjects made a button press response in an attempt to gain or avoid losing the money. Subjects were instructed to respond to neutral targets despite the lack of incentive value. A feedback message then informed them of the trial outcome. The incentive trials were presented in a pseudorandom order. The duration of the response target was calculated based on the individual subject’s reaction time during a practice session prior to scanning and dynamically adjusted during the task such that overall success rate was $\sim 60 \%$ (Yau et al., 2012). Participants were paid fixed participation rates plus additional money won during the task. 
Risk and NAcc Reward Response

fMRI imaging. Whole-brain BOLD functional images were acquired on a 3.0 Tesla GE Signa scanner (Milwaukee, WI) using T2*-weighted single-shot combined spiral in/out sequences (Glover and Law 2001), parameters: repetition time (TR)=2000 ms, echo time $(\overline{T E})=30 \mathrm{~ms}$, flip angle $(\mathrm{FA})=90^{\circ}$; field-of-view $(\mathrm{FOV})=200 \mathrm{~mm}$; matrix size $=64 \times 64$;

slice thickness $=4 \mathrm{~mm}, 29$ slices. High-resolution anatomical T1 scans were obtained for spatial normalization. Motion was minimized with foam pads and emphasis on importance of keeping still.

fMRI image processing. Functional images were reconstructed using an iterative algorithm and motion corrected using statistical parametric mapping (SPM8, Wellcome Institute of Cognitive Neurology, Oxford, UK). All runs for all subjects met the motion inclusion criteria of less than $2 \mathrm{~mm}$ translation or $2^{\circ}$ rotation. Images were spatially normalized to Montreal Neurological Institute space and spatially smoothed with a $6 \mathrm{~mm}$ isotropic kernel. A GLM using SPM’s canonical hemodynamic response function, modeled all events (cues: win $\$ 0.20$, win $\$ 5.0$, lose $\$ 0.20$, lose $\$ 5.0$ and neutral $\$ 0$; anticipation delay for each cue type; positive outcome for each cue type; negative outcome for each cue type) incentive anticipation for each cue type (\$0.20 win, \$1.00 win, $\$ 5.00$ win, $\$ 0.20$ loss, $\$ 1.00$ loss, $\$ 5.00$ loss, $\$ 0$ ) convolved with the canonical hemodynamic response function. In addition, regressors for six motion parameters and white matter signal intensity were included to reduce residual motion artifacts and capture non-task-related noise. Contrasts for anticipation of monetary gain trials $(\$ 0.20$, $\$ 1.00$ and $\$ 5.00$ combined) versus neutral trials and feedback of positive monetary gain 
trials versus of negative monetary gain trials were calculated for each individual. These contrasts, referred to as "reward anticipation" and "reward feedback" for the remainder of the text, were for used in second-level one-sample t-test and correlation analyses. Loss contrasts were not further analyzed for this study. Again, with a priori interest in the ventral striatum, left and right NAcc ROI effect sizes were calculated from parameter estimates using the MarsBaR toolbox using anatomical masks as described in previous work (Bjork et al., 2008; Yau et al., 2012).

Statistical Analyses. All data were analyzed using the Statistical Package of Social Sciences-22 (SPSS-22). Group differences in scan age were assessed using a generalized linear model with three levels for group (FH- Control, FH+ Low Risk, FH+ High Risk). There was an effect of group $\left(\mathrm{F}_{2,43}=4.11, \mathrm{p}=0.024\right)$, which was driven by an older mean age in the FH+ High-Risk group versus the FH- Controls $(24.2 \pm 2.9$ years > 20.6 \pm 2.7 years, $t=0.2 .875, p=0.01$ ); therefore scan age was used as a covariate in the remainder of statistical analyses. Data distribution was assessed using the KolmogorovSmirnov Z-test; drug use variables did not meet the assumption of normality and were log transformed (after first adding one to each value). Due to high collinearity of reported use of alcohol, tobacco and marijuana, principal component analysis of lifetime cumulative use was performed, resulting in a one factor solution explaining $66.4 \%$ of the variance (factor loadings: cumulative drink volume $=0.887$, cumulative cigarette smoking days $=$ 0.720 , cumulative marijuana smoking days $=0.828$ ). This factor was used as a covariate when assessing group differences in PET and fMRI measures. GLMs were used to assess 
group differences modeling two levels of the within-subject factor hemisphere (left and right) and three levels of the between-subject factor, group (FH- Control, FH+ Low Risk, FH+ High Risk). With concern that nonspecific effects were part of the structure of influence when including the general consumption factor, these analyses were repeated excluding this factor. However, statistics for GLMs with and without the consumption $= \pm$ factor were essentially the same so the latter are not reported in results. Finally, as exploratory analyses, partial correlations, controlling for scan age and the cumulative substance use factor, were used to assess relationships between PET and fMRI data and substance use measures.

\section{RESULTS}

Subject Characteristics. Forty-four subjects (age: range, mean \pm standard deviation: 18.0

- 26.7, 22.91 \pm 3.0 years) were recruited into the study comprising three groups: FHcontrol subjects and two FH+ groups differentiated as Low or High Risk with the latter having initiated drunkenness by age 15. Subject characteristics are presented in Table 1. There were no significant differences in demographic, personality, or substance use measures between the FH- Control and FH+ Low Risk groups (p’s > 0.153). The FH+ groups differed on sensation-seeking and all cumulative substance use measures (with the exception of number of cigarette smoking days). For past month use, the FH+ High Risk group reported more alcohol but not cigarette or marijuana use. With the exception of a single subject from the FH+ Low Risk group reporting use of vicodin, no subjects reported recent use of other illicit substances. 
Risk and NAcc Reward Response

MID task during PET. $\mathrm{BP}_{\mathrm{ND}}$ for the control condition, somewhat a proxy for baseline D2/D3 receptor availability, did not differ between groups for the NAcc ROIs (p's > 0.795) although there was an effect of age significant in the left but not right NAcc (L/R: $\mathrm{F}_{1,43}=4.763, \mathrm{p}=0.035 ; \mathrm{F}_{2,43}=2.861, \mathrm{p}=0.099$ ). Across all subjects, the NAcc ROIs demonstrated modest, non-significant behavioral reward-induced reductions in the $=$ receptor availability measure, $\mathrm{BP}_{\mathrm{ND}}$, consistent with the activation of DA D2/D3 neurotransmission (paired t-tests, L/R: $\mathrm{t}=-1.277, \mathrm{p}=0.104 ; \mathrm{t}=-1.343, \mathrm{p}=0.093$, onetailed). However, for the FH+ High Risk group, the effect was significant (L/R: t = 3.013, $\mathrm{p}=0.009 ; \mathrm{t}=-3.198 ; \mathrm{p}=0.007$ ), suggestive of positive DA release in response to the task. The GLM analysis of $\triangle \mathrm{BP} \mathrm{ND}_{\mathrm{ND}}$, indicative of dopamine response/release, identified an effect of group in the NAcc ROIs, $\left(\mathrm{L} / \mathrm{R}: \mathrm{F}_{2,43}=6.278, \mathrm{p}=0.004 ; \mathrm{F}_{2,43}=\right.$ 3.157, $\mathrm{p}=0.054$ ), see Figure 2. See Supplemental Table 1 for $\mathrm{BP}_{\mathrm{ND}}$ values for ROIs for each task condition.

To insure that alcohol or marijuana dependence was not driving this finding, we repeated this analysis excluding the individuals $(\mathrm{FH}-$ Control, $\mathrm{n}=1$; FH+ High Risk, $\mathrm{n}=$ 1) who had met diagnoses, still finding a group effect in both the left $\left(\mathrm{F}_{2,41}=7.783, \mathrm{p}=\right.$ $0.008)$ and right NAcc $\left(F_{2,41}=6.506, \mathrm{p}=0.015\right)$

MID task during fMRI. The GLM analyses of neural task activation did not identify an effect of group in the NAcc ROIs for reward anticipation (p’s > 0.326) or reward feedback (p’s > 0.769), see Figure 2. 
Risk and NAcc Reward Response

Correlation of PET and fMRI data. Across all subjects, NAcc DA release was not related to BOLD activation during reward anticipation (p’s > 0.242) but was positively correlated with activation during reward feedback (L/R: $r=0.418, p=0.006 ; r=0.393, p$ $=0.010)$. Thus, a negative striatal $\Delta \mathrm{BP}_{\mathrm{ND}}$, or positive dopamine response/release during the PET version of the MID task, correlated with increased striatal activation during the $=$ positive notification of reward receipt during the fMRI version of the MID task, see Figure 3.

Correlation of PET and fMRI data with substance use. No associations were found with ventral striatal DA release, anticipatory response, or feedback response with the cumulative substance use measure. For all subjects, DA release was negatively associated with age of first drunk in the left NAcc $(\mathrm{t}=-0.455, \mathrm{p}=0.017)$ showing a trend in the right NAcc $(t=-0.363, p=0.063)$, see Figure 4 , such that subjects that experienced drunkenness at a younger age had higher ventral striatal release during the MID task in the PET study. Age of first drink was negatively associated with NAcc reward feedback neural activation during the MID task in the fMRI study (L/R: $r=0.378, p=0.030 ; \mathrm{r}=$ 0.467, $\mathrm{p}=0.006)$

\section{DISCUSSION}

Given the key role for the NAcc in reward processing and reinforcement, D2/D3 receptor availability and dopamine neurotransmission in this structure has been suggested as a potential biomarker for vulnerability for substance use disorders, particularly in 
Risk and NAcc Reward Response

individuals with familial loading (Trifilieff and Martinez, 2014a). The present study used multimodal imaging to evaluate reward responsivity in at-risk individuals using both PET and fMRI. We report that FH+ subjects who report early drunkenness have heightened striatal dopamine response to monetary reward than either FH+ or FH- control subjects. Further, for all subjects, higher ventral striatal dopamine release was associated with earlier age of first drunkenness. In addition, we found no group differences, by family history or early risk, in neural reactivity to monetary reward anticipation or feedback but we report across all subjects a positive relationship between dopaminergic release and neural response to reward receipt. These results suggest that in $\mathrm{FH}+$ individuals, greater dopamine release associated with monetary reward may represent a particularly useful neurobiological phenotype. Further, a behaviorally-induced method to interrogate dopamine function may be both practical, and in some cases, preferable to probing this system pharmacologically.

Much of the previous work evaluating the responsivity of the dopamine reward system has used stimulant challenges. Some early, important PET studies of substance use reported negative relationships between D2 receptor availability and self-reported pleasurable response to methylphenidate (Volkow et al., 1999). These studies were followed with reports finding attenuated response to amphetamine administration in both alcohol (Martinez et al., 2005; Volkow et al., 2007) and cocaine (Martinez et al., 2007; Volkow et al., 1997) dependent individuals. Moving the focus from substance-abusing populations to those at-risk, similar attenuated response to amphetamine was reported in 
$\mathrm{FH}+$ subjects that engaged in recreational use of psychostimulants compared with $\mathrm{FH}$ subjects that were drug-naïve as well as those with matched drug use (Casey et al., 2014). While a conflicting study reported no differences in striatal amphetamine response associated with familial loading (Munro et al., 2006), the level of risk in the latter study was lower both in terms of loading (fewer affected relatives) and behavior (less substance $=$ use).

Other work has evaluated striatal dopamine response following alcohol consumption. In healthy individuals, increased striatal response followed oral consumption in some studies (Boileau et al., 2003; Urban et al., 2010), but not all (Yoder et al., 2005), with responses potentially dependent on spatial determination of striatal release (Yoder et al., 2007) or genetic polymorphisms (Ramchandani et al., 2011). With respect to risk, Setiawan and colleagues found that subjects designated high-risk based on subjective sensitivity to alcohol had increased dopamine transmission following an oral challenge, and higher familial loading, than subjects with lower sensitivity (Setiawan et al., 2014).

Given the heterogeneous results of both stimulant and alcohol induction of dopamine response, as well as a concern of using drug challenges in at-risk populations, the use of the MID task in PET studies represents a feasible method of discriminating risk. Our results suggest that high-risk subjects, indexed by their early intoxication, have increased response to monetary reward. The current levels of alcohol consumption ( 12 drinks/week) are similar to those of the high-risk group in the alcohol challenge study 
Risk and NAcc Reward Response

( 13 drinks/week) by Setiawan et al. (2014). In fact, both the present study and that study lend support to a recent neurodevelopmental model of vulnerability to addiction presented by Leyton and Vezina (2014). This model hypothesizes that vulnerable individuals may have heightened responsivity to a variety of salient stimuli which may translate into risk-taking behaviors, including experimentation with drugs. If substance use is initiated and continued, this use would become associated with cues through conditioning and sensitization, eventually leading to accentuated response to drug-cues and attenuated response to non-drug rewards (Leyton and Vezina, 2014). In support of this model, Casey et al. has shown that current substance users had low dopamine release associated with an amphetamine challenges which had no drug cues present (Casey et al., 2014) in contrast to the increased dopamine release associated with an alcohol challenge which involves multiple sensory cues associated with oral consumption (Setiawan et al., 2014). Given that none of our high-risk subjects have reached a diagnosis of alcohol dependence, and analysis without the single subject with a marijuana dependence diagnosis had no effect on our findings, we would suggest that these subjects are still in the 'early' vulnerability stage where the reward system has not become conditioned to focus on drug cues. Continued longitudinal scans, which are ongoing in our sample, may potentially identify a transition in cue responding in those subjects who reach diagnosis in the future. In addition, our lack of group differences, either by family history or risk level, in binding levels during the control condition, while not the conventional method of measurement, may suggest that preexisting receptor levels are not contributing to risk. 
Risk and NAcc Reward Response

In addition to dopamine $\mathrm{BP}_{\mathrm{ND}}$ and release, neural reward responsivity has also been investigated as a potential biomarker of risk. For example, our prior work reported blunted activation to reward anticipation in $\mathrm{FH}+$ young adults with low levels of alcohol use compared with FH- young adults (Yau et al., 2012). However, FH+ young adults who were risky drinkers did not differ from FH- young adults matched on drinking, which suggests that blunted activation may be a resilience mechanisms in FH+. In a follow-up repeated measures analysis with a larger sample $(n=175$; scans $=473)$, across a larger age range (8-27 years), we did not find an effect of family history but reported a quadratic association with age where adolescents displayed amplified striatal response which was related to later problem alcohol use (Heitzeg et al., 2014). Indeed, the literature has been heterogeneous in establishing a familial effect, with some studies reporting differences based on family loading (i.e. (Andrews et al., 2011; Yau et al., 2012) while others - notably in younger samples - have not (i.e. (Bjork et al., 2008; Müller et al., 2014). This heterogeneity may be related not only to development, but also to variations in task design and analysis methods (Balodis and Potenza; Hommer et al., 2011). The lack of a family history effect is in agreement with our more recent work (Heitzeg et al., 2014) but may also be partly attributable to the relatively small sample size of the current study as an fMRI experiment.

Of particular interest, we report a positive relationship between striatal dopamine release associated with monetary reward and neural activation associated with positive reward feedback across all subjects. Other work using the MID in both PET and fMRI 
has reported a relationship between ventral striatal dopamine release and anticipatory accumbens activation with the suggestion that either local dopamine release may trigger local blood oxygenation level dependent signal or, conversely, be the consequence of increased neural activation (Schott et al., 2008). Given the larger sample size in this study $(n=44)$ compared to Schott et al $(n=14)$, it is interesting that we did not duplicate their $=$ finding. That study performed a regression between NAcc dopamine release and anticipatory response but not feedback response. Dependent on study design, there is often considerable collinearity and potential confound between the anticipatory and feedback responses. Other fMRI studies have demonstrated that feedback of performance activates the ventral striatum (Aron et al., 2004; Lutz et al., 2012) and, in fact, as opposed to the dorsal striatum, its activation is increased by feedback when a monetary incentive in present (Lutz et al., 2012). Removal of a monetary incentive leads to a significant drop in activation (Murayama et al., 2010) suggesting that feedback itself may serve as a task intrinsic reward (Lutz and Widmer, 2014). As dopamine release during a video game has been shown to positively correlate with task performance (Koepp et al., 1998), our study importantly links ventral striatal dopamine release with neural response to feedback. This may be a step in understanding the mechanisms of intrinsically motivated behaviors.

It is important to acknowledge that, in contrast to our original study of the MID task to induce dopamine release (Weiland et al., 2014), we did not see a strong effect of task in this study. To reduce experimental complexity, the former study was limited to 
females. However, the current study enrolled only male subjects to increase rates of highrisk behavior in the sample. For several methodological reasons - including age range, familial liability, different versions of the fMRI task, etc. - these groups are not easily compared. We note, however, that other work has demonstrated greater dopamine release in many regions of the brain (with the exception of the dorsal striatum) in women (Riccardi et al., 2006). The fact that the task effect was highly significant in the High Risk group may support the use of behaviorally-induced dopamine release as a potential biomarker, particularly in male subjects. Given demonstrated sex differences in dopamine response (Riccardi et al., 2006; Urban et al., 2010), further work is needed to examine the relationships between behavioral and pharmacological response to reward in both sexes.

In summary, we find that behavioral induction of dopamine release may be a phenotypic marker of risk for substance use. Subjects with familial liability for risk that have also engaged in early drunkenness displayed higher ventral striatal dopamine response during a monetary task despite no differences in initial receptor levels. Given the challenges associated with pharmacological interrogation of reward systems, behavioral-induction of dopamine response may lead to a better understanding of molecular mechanisms underlying risk.

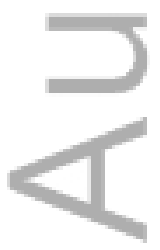




\section{FIGURE LEGENDS}

Figure 1. A) Schematic of reward condition of PET paradigm: Trials followed the same timing as the fMRI paradigm presented in a single run of 30 minutes with reward and loss cues. Novel changes to cues and feedback were added over time including color and sound to maintain subject interest. A control condition presenting a neutral cue and target with no feedback was presented during a separate single 30 minute run. B) Schematic of fMRI paradigm: A single trial of 6 seconds consisted of 2000 ms each for cue; anticipation; and target plus feedback. Subjects complete 2 runs of 5 minutes each. Reward, loss, and neutral cues were counterbalanced and presented pseudorandomly throughout each run.

Figure 2. A) Location of NAcc regions of interest. Group comparisons of B) dopamine release (Effect of group: ${ }^{*} \mathrm{p}=0.004,{ }^{\dagger} \mathrm{p}=0.054$ ), $\mathrm{C}$ ) neural activation in response to reward anticipation, and D) reward feedback.

Figure 3. Scatter plots of MID response captured by PET and fMRI: NAcc BOLD response during reward anticipation and feedback versus dopamine release for the left and right nucleus accumbens by group. Correlations between dopamine release and BOLD response during reward anticipation were not significant (p’s > 0.242) but were for feedback (L/R: p = 0.006/0.010).

Figure 4. Scatter plots of NAcc dopamine release versus age of first drunkenness by group.

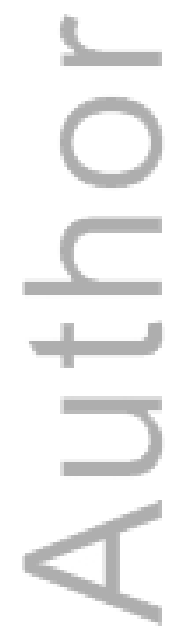


Table 1. Subject Characteristics.

\begin{tabular}{|c|c|c|c|c|c|}
\hline \multirow[b]{2}{*}{ Measure } & \multirow[b]{2}{*}{$\begin{array}{c}\text { FH- } \\
\text { Control }\end{array}$} & \multirow[b]{2}{*}{$\begin{array}{c}\text { FH+ } \\
\text { Low Risk }\end{array}$} & \multirow[b]{2}{*}{$\begin{array}{c}\text { FH+ } \\
\text { High Risk }\end{array}$} & \multicolumn{2}{|c|}{$\begin{array}{c}\text { FH+ Low versus } \\
\text { High Risk }\end{array}$} \\
\hline & & & & $\mathbf{t}$ & Sig \\
\hline 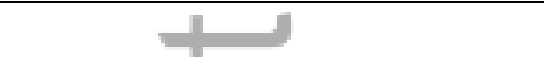 & & & & & \\
\hline $\mathrm{N}$ & 11 & 24 & 9 & & \\
\hline Age - At Scan (years) & $20.6(2.7)$ & $22.0(2.8)$ & $24.2(2.9)$ & -1.92 & 0.064 \\
\hline Family Expression AUD & $0.02(.03)$ & $0.68(0.37)$ & $0.56(0.42)$ & 0.62 & 0.543 \\
\hline $\mathrm{IQ}^{\mathrm{a}}$ & 108 & $106(12)$ & $112(12)$ & -1.23 & 0.228 \\
\hline \multicolumn{6}{|l|}{ Past Month Substance Use } \\
\hline Alcohol (standard drinks) & $12.4(18.4)$ & $5.7(9.3)$ & $50.9(97.0)$ & -2.32 & 0.027 \\
\hline Cigarettes (\#) & $23.1(76.6)$ & $15.7(44.4)$ & $42.8(122.4)$ & -0.95 & 0.350 \\
\hline Marijuana (\# of joints) & $2.90(7.00)$ & $1.46(6.11)$ & $21.11(48.85)$ & -1.98 & 0.056 \\
\hline \multicolumn{6}{|l|}{ Cumulative Substance Use } \\
\hline Cumulative Drink Volume & 713 (1103) & 882 (1403) & 3967 (3721) & -3.52 & 0.001 \\
\hline \# Binge Drinking Days & $61(134)$ & $82(160)$ & 304 (233) & -3.13 & 0.004 \\
\hline \# Days of Cigarette Smoking & 203 (329) & 209 (423) & $631(977)$ & -1.76 & 0.089 \\
\hline \# Days of Marijuana Use & $174(556)$ & $34(112)$ & $520(589)$ & -3.95 & $<0.001$ \\
\hline \# Alcohol Related Problems & $2.8(4.3)$ & $3.0(3.8)$ & $9.8(5.2)$ & -4.16 & $<0.000$ \\
\hline \# Drug Related Problems & $0.18(0.60)$ & $0.13(0.45)$ & $1.22(1.72)$ & -2.94 & 0.006 \\
\hline Impulsivity & $1.72(1.42)$ & $2.58(2.48)$ & $2.56(2.50)$ & 0.03 & 0.977 \\
\hline Sensation Seeking ${ }^{\mathrm{b}}$ & $6.09(2.12)$ & $6.13(2.97)$ & $8.67(2.18)$ & -2.33 & 0.026 \\
\hline Resiliency $^{\mathrm{c}}$ & $6.41(1.02)$ & $6.42(0.96)$ & $6.28(0.92)$ & 0.37 & 0.714 \\
\hline Reactive Control $^{\mathrm{C}}$ & $5.28(0.86)$ & $5.06(0.91)$ & $4.64(1.05)$ & 1.15 & 0.260 \\
\hline Negative Emotionality $^{c}$ & $3.62(1.17)$ & $3.54(0.97)$ & $3.72(1.04)$ & -0.48 & 0.636 \\
\hline \multicolumn{6}{|l|}{ Age of Initial } \\
\hline First Drink & $16.2(1.5)$ & $15.8(3.4)$ & $11.9(1.8)$ & 3.23 & 0.003 \\
\hline First Drunk & $17.8(1.1)$ & $18.1(2.0)$ & $13.9(1.2)$ & 5.50 & $<0.001$ \\
\hline First Marijuana Use & $15.7(1.1)$ & $17.0(3.3)$ & $15.4(3.5)$ & 0.99 & 0.339 \\
\hline First Cigarette Use & $16.6(0.7)$ & $16.6(1.3)$ & $17.2(3.0)$ & -0.53 & 0.607 \\
\hline $\begin{array}{l}\text { First Illicit Drug Use Other } \\
\text { Than Marijuana }\end{array}$ & $18.7(4.1)$ & $16.6(3.8)$ & $17.1(2.6)$ & -0.22 & 0.833 \\
\hline \multicolumn{6}{|l|}{ Diagnoses } \\
\hline Alcohol Abuse & 0 & 1 & 2 & & ns \\
\hline Alcohol Dependence & 0 & 0 & 0 & & ns \\
\hline Marijuana Abuse & 1 & 0 & 1 & & ns \\
\hline Marijuana Dependence & 0 & 0 & 1 & & ns \\
\hline
\end{tabular}


Nicotine Dependence

Other Substance Abuse ${ }^{\mathrm{e}}$

Other Substance Dependence ${ }^{\mathrm{e}} \quad 0$

Major Depression Disorder 0

Anxiety Disorder 0

$\begin{array}{llll}0 & 0 & \text { ns }\end{array}$

$\begin{array}{llll}0 & 0 & 0 & \text { ns }\end{array}$

$\begin{array}{llll}0 & 0 & \text { ns }\end{array}$

Externalizing Behavior 4

Attention Deficit Disorder 2

Conduct Disorder

2

ns

$\begin{array}{llll}0 & 0 & \text { ns }\end{array}$

$\begin{array}{llll}7 & 4 & \text { ns }\end{array}$

Data Presented as Mean (Standard Deviation) where applicable.

Significant values in bold at $\alpha=0.05$.

${ }^{a}$ Wechsler Intelligence Scale for Children $-3^{\text {rd }}$ edition or Revised WISC. These data were collected when participants were between the ages of 12 and 14 years as part of the ongoing Michigan Longitudinal Study.

b Zuckerman Impulsivity and Sensation Seeking Scale (Zuckerman, 1972)

${ }^{c}$ Q-Sort Eisenberg temperament scale (Eisenberg et al., 1997)

d Annual assessments using Drinking and Drug History Form (DDHx) since age 11 through scan age; abuse and dependence diagnoses based on Diagnostic Interview Schedule for DSM-IV Child Version, assessed for five years prior to scan ;data presented as number of individuals per group meeting diagnoses.

e Includes any of the following: amphetamines, cocaine, sedatives/hypnotics, or opiates.

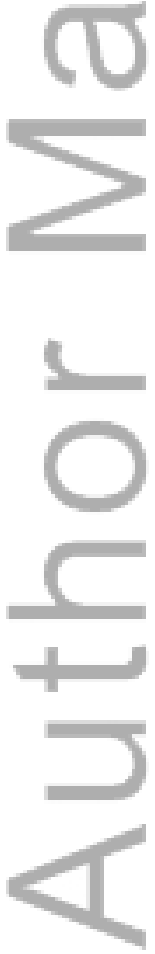


Risk and NAcc Reward Response

\section{REFERENCES}

Andrews MM, Meda SA, Thomas AD, Potenza MN, Krystal JH, Worhunsky P, Stevens MC, O'Malley S, Book GA, Reynolds B, Pearlson GD (2011) Individuals Family History Positive for Alcoholism Show Functional Magnetic Resonance Imaging Differences in Reward Sensitivity That Are Related to Impulsivity Factors. Biological Psychiatry 69:675-683.

Aron AR, Shohamy D, Clark J, Myers C, Gluck MA, Poldrack RA (2004) Human Midbrain Sensitivity to Cognitive Feedback and Uncertainty During Classification -Learning. Journal of Neurophysiology 92:1144-1152.

Balodis IM, Potenza MN (2015) Anticipatory Reward Processing in Addicted Populations: A Focus on the Monetary Incentive Delay Task. Biological Psychiatry 77:434-444.

Bjork JM, Knutson B, Hommer DW (2008) Incentive-elicited striatal activation in adolescent children of alcoholics. Addiction 103:1308-1319.

Boileau I, Assaad JM, Pihl RO, Benkelfat C, Leyton M, Diksic M, Tremblay RE, Dagher A (2003) Alcohol promotes dopamine release in the human nucleus accumbens. Synapse 49:226-231.

Carson RE, Breier A, de Bartolomeis A, Saunders RC, Su TP, Schmall B, Der MG, Pickar D, Eckelman WC (1997) Quantification of Amphetamine-Induced Changes in [11C] Raclopride Binding with Continuous Infusion. Journal of Cerebral Blood Flow \& Metabolism 17:437-447.

Casey KF, Benkelfat C, Cherkasova MV, Baker GB, Dagher A, Leyton M (2014) Reduced dopamine response to amphetamine in subjects at ultra-high risk for addiction. Biol Psychiatry 76:23-30.

Eisenberg N, Guthrie IK, Fabes RA, Reiser M, Murphy BC, Holgren R, Maszk P, Losoya $S$ (1997) The relations of regulation and emotionality to resiliency and competent social functioning in elementary school children. Child Dev 68:295-311.)

Heitzeg MM, Villafuerte S, Weiland BJ, Enoch M-A, Burmeister M, Zubieta J-K, Zucker RA (2014) Effect of GABRA2 Genotype on Development of Incentive-Motivation Circuitry in a Sample Enriched for Alcoholism Risk. Neuropsychopharmacology 39:3077-3086.

Hommer DW, Bjork JM, Gilman JM (2011) Imaging brain response to reward in addictive disorders. Annals of the New York Academy of Sciences 1216:50-61.

Innis RB, Cunningham VJ, Delforge J, Fujita M, Gjedde A, Gunn RN, Holden J, Houle S, Huang SC, Ichise M, lida H, Ito H, Kimura Y, Koeppe RA, Knudsen GM, Knuuti J, Lammertsma AA, Laruelle M, Logan J, Maguire RP, Mintun MA, Morris ED, Parsey R, Price JC, Slifstein M, Sossi V, Suhara T, Votaw JR, Wong DF, Carson RE (2007) Consensus nomenclature for in vivo imaging of reversibly binding radioligands. Journal of Cerebral Blood Flow \& Metabolism 27:1533-1539.

Johnston LD, O'Malley PM, Backman JG (1996) National survery results on drug use from the "Monitoring the Future" study, 1975-1995: Vol.1: Secondary School Students. National Institute on Drug Abuse: Rockville, MD. 
Knutson B, Fong GW, Adams CM, Varner JL, Hommer D (2001) Dissociation of reward anticipation and outcome with event-related fMRI. Neuroreport 12:3683-3687.

Koepp MJ, Gunn RN, Lawrence AD, Cunningham VJ, Dagher A, Jones T, Brooks DJ, Bench CJ, Grasby PM (1998) Evidence for striatal dopamine release during a video game. Nature 393:266-268.

Leyton M, Vezina P (2014) Dopamine ups and downs in vulnerability to addictions: a neurodevelopmental model. Trends in Pharmacological Sciences 35:268-276.

Lutz K, Pedroni A, Nadig K, Luechinger R, Jancke L (2012) The rewarding value of good motor performance in the context of monetary incentives. Neuropsychologia 50:17391747.

Lutz K, Widmer M (2014) What can the monetary incentive delay task tell us about the neural processing of reward and punishment? Neuroscience and Neuroeconomics:33.

Martinez D, Gil R, Slifstein M, Hwang DR, Huang Y, Perez A, Kegeles L, Talbot P, Evans S, Krystal J, Laruelle M, Abi-Dargham A (2005) Alcohol Dependence Is Associated with Blunted Dopamine Transmission in the Ventral Striatum. Biol Psychiatry.

Martinez D, Narendran R, Foltin RW, Slifstein M, Hwang D-R, Broft A, Huang Y, Cooper TB, Fischman MW, Kleber HD, Laruelle M (2007) Amphetamine-Induced Dopamine Release: Markedly Blunted in Cocaine Dependence and Predictive of the Choice to Self-Administer Cocaine. Am J Psychiatry 164:622-629.

Minoshima S, Koeppe RA, Mintun MA, Berger KL, Taylor SF, Frey KA, Kuhl DE (1993) Automated detection of the intercommissural line for stereotactic localization of functional brain images. Journal of Nuclear Medicine 34:322-329.

Müller KU, Gan G, Banaschewski T, Barker GJ, Bokde ALW, Büchel C, Conrod P, Fauth-Bühler M, Flor H, Gallinat J, Garavan H, Gowland P, Heinz A, Ittermann B, Lawrence C, Loth E, Mann K, Martinot J-L, Nees F, Paus T, Pausova Z, Rietschel M, Ströhle A, Struve M, Schumann G, Smolka MN, Consortium I (2014) No differences in ventral striatum responsivity between adolescents with a positive family history of alcoholism and controls. Addiction Biology:n/a-n/a.

Munro CA, McCaul ME, Oswald LM, Wong DF, Zhou Y, Brasic J, Kuwabara H, Kumar A, Alexander M, Ye W, Wand GS (2006) Striatal Dopamine Release and Family History of Alcoholism. Alcoholism: Clinical and Experimental Research 30:1143-1151.

Murayama K, Matsumoto M, Izuma K, Matsumoto K (2010) Neural basis of the undermining effect of monetary reward on intrinsic motivation. Proc Natl Acad Sci U S A 107:20911-20916.

National Institute on Alcohol Abuse and Alcoholism (2000) Alcohol involvement over the life course. In: NIAAA, Tenth Special Report to the US Congress on Alcohol and

Health: Highlights from current research. U.S. Department of Health and Human Services: Bethesda, MD. pp 28-53.

Nestler EJ (2000) Genes and addiction. Nature Genetics 26:277-281.

Ramchandani VA, Umhau J, Pavon FJ, Ruiz-Velasco V, Margas W, Sun H, Damadzic R, Eskay R, Schoor M, Thorsell A, Schwandt ML, Sommer WH, George DT, Parsons LH, Herscovitch P, Hommer D, Heilig M (2011) A genetic determinant of the striatal dopamine response to alcohol in men. Mol Psychiatry 16:809-817. 
Riccardi P, Zald D, Li R, Park S, Ansari MS, Dawant B, Anderson S, Woodward N, Schmidt D, Baldwin R, Kessler R (2006) Sex Differences in Amphetamine-Induced Displacement of [18F]Fallypride in Striatal and Extrastriatal Regions: A PET Study. The American Journal of Psychiatry 163:1639-1641.

Schott BH, Minuzzi L, Krebs RM, Elmenhorst D, Lang M, Winz OH, Seidenbecher Cl, Coenen HH, Heinze HJ, Zilles K, Duzel E, Bauer A (2008) Mesolimbic functional magnetic resonance imaging activations during reward anticipation correlate with reward-related ventral striatal dopamine release. The Journal of Neuroscience 28:14311-14319.

Seeman P, Bzowej NH, Guan HC, Bergeron C, Becker LE, Reynolds GP, Bird ED,

$=$ Riederer $\mathrm{P}$, Jellinger K, Watanabe S, et al. (1987) Human brain dopamine receptors in children and aging adults. Synapse 1:399-404.

Seeman P, Wilson A, Gmeiner P, Kapur S (2006) Dopamine D2 and D3 receptors in human putamen, caudate nucleus, and globus pallidus. Synapse 60:205-211.

Setiawan E, Pihl RO, Dagher A, Schlagintweit H, Casey KF, Benkelfat C, Leyton M (2014) Differential striatal dopamine responses following oral alcohol in individuals at varying risk for dependence. Alcohol Clin Exp Res 38:126-134.

Sobell LC, Sobell MB (1992) Timeline follow-back: a technique for assessing selfreported alcohol consumption. In: Measuring Alcohol Consumption: Psychosocial and Biochemical Methods. Litten RZ, Allen JP (eds). The Umana Press Inc.: New Jersey, USA. pp 41-72.

Spak L, Spak F, Allebeck P (1997) Factors in childhood and youth predicting alcohol dependence and abuse in Swedish women: findings from a general population study. Alcohol Alcohol 32:267-274.

Trifilieff P, Martinez D (2014a) Blunted dopamine release as a biomarker for vulnerability for substance use disorders. Biol Psychiatry 76:4-5.

Trifilieff P, Martinez D (2014b) Imaging addiction: D2 receptors and dopamine signaling in the striatum as biomarkers for impulsivity. Neuropharmacology 76, Part B:498-509.

Urban NBL, Kegeles LS, Slifstein M, Xu X, Martinez D, Sakr E, Castillo F, Moadel T, O'Malley SS, Krystal JH, Abi-Dargham A (2010) Sex Differences in Striatal Dopamine Release in Young Adults After Oral Alcohol Challenge: A Positron Emission Tomography Imaging Study With [11C]Raclopride. Biological Psychiatry 68:689-696.

Volkow ND, Wang GJ, Begleiter H, Porjesz B, Fowler JS, Telang F, Wong C, Ma Y, Logan J, Goldstein R, Alexoff D, Thanos PK (2006) High levels of dopamine D2 receptors in unaffected members of alcoholic families: possible protective factors. Arch Gen Psychiatry 63:999-1008.

Volkow ND, Wang GJ, Fowler JS, Logan J, Gatley SJ, Gifford A, Hitzemann R, Ding YS, Pappas N (1999) Prediction of reinforcing responses to psychostimulants in humans by brain dopamine D2 receptor levels. Am J Psychiatry 156:1440-1443.

Volkow ND, Wang GJ, Fowler JS, Logan J, Gatley SJ, Hitzemann R, Chen AD, Dewey SL, Pappas N (1997) Decreased striatal dopaminergic responsiveness in detoxified cocaine-dependent subjects. Nature 386:830-833.

Volkow ND, Wang GJ, Telang F, Fowler JS, Logan J, Jayne M, Ma Y, Pradhan K, Wong C (2007) Profound decreases in dopamine release in striatum in detoxified alcoholics: possible orbitofrontal involvement. J Neurosci 27:12700-12706. 
Risk and NAcc Reward Response

Weiland BJ, Heitzeg MM, Zald D, Cummiford C, Love T, Zucker RA, Zubieta J-K (2014) Relationship between impulsivity, prefrontal anticipatory activation, and striatal dopamine release during rewarded task performance. Psychiatry Research: Neuroimaging 223:244-252.

Yau WY, Zubieta JK, Weiland BJ, Samudra PG, Zucker RA, Heitzeg MM (2012) Nucleus accumbens response to incentive stimuli anticipation in children of alcoholics: relationships with precursive behavioral risk and lifetime alcohol use. J Neurosci 32:2544-2551.

Yoder KK, Constantinescu CC, Kareken DA, Normandin MD, Cheng TE, O'Connor SJ, Morris ED (2007) Heterogeneous effects of alcohol on dopamine release in the striatum: a PET study. Alcohol Clin Exp Res 31:965-973.

Yoder KK, Kareken DA, Seyoum RA, O'Connor S J, Wang C, Zheng QH, Mock B, Morris ED (2005) Dopamine $D(2)$ receptor availability is associated with subjective responses to alcohol. Alcohol Clin Exp Res 29:965-970.

Zald DH, Boileau I, El-Dearedy W, Gunn R, McGlone F, Dichter GS, Dagher A (2004) Dopamine Transmission in the Human Striatum during Monetary Reward Tasks. Journal of Neuroscience 24:4105-4112.

Zucker R, Fitzgerald H, Noll R (1990) Drinking and Drug History (Revised edition, Version 4). University of Michigan Department of Psychiatry, Addiction Research Center: Ann Arbor.

Zucker RA, Ellis DA, Fitzgerald HE, Bingham CR, Sanford K (1996) Other evidence for at least two alcoholisms II: Life course variation in antisociality and heterogeneity of alcoholic outcome. Development and Psychopathology 8:831-848.

Zucker RA, Fitzgerald HE, Refior SK, Puttler LI, Pallas DM, Ellis DA (2000) The clinical and social ecology of childhood for children of alcoholics: Description of a study and implications for a differentiated social policy. In: Children of addiction: Research, Health and Policy Issues. Fitzgerald HE, Lester BM, Zuckerman BS (eds). Routledge Falmer: New York. pp 109-141.

Zuckerman, M, 1972. Drug usage as one manifestation of a sensation seeking trait. In: Keup, W. (Ed.), Drug Abuse; Current Concepts and Research. Charles Thomas, Springfield, IL, pp. 154-163

This article is protected by copyright. All rights reserved. 


\section{A. PET Paradigm}

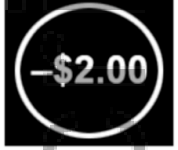

Time (30 min/run)

Figure 1

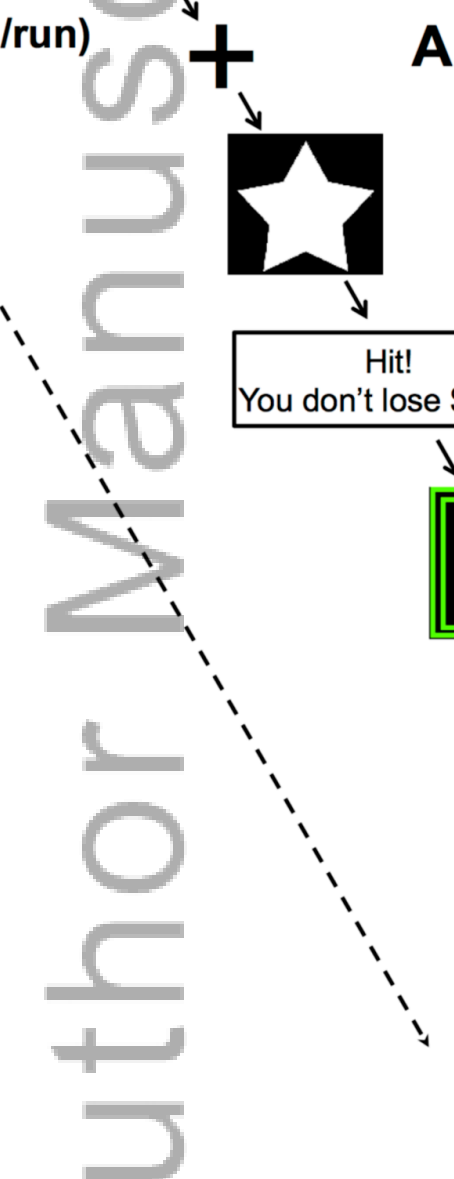

Anticipation

\section{Target}
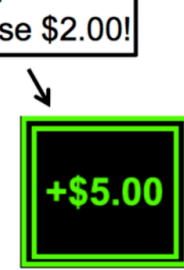

Feedback

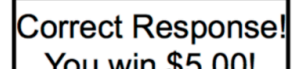
$\$ 5.00$

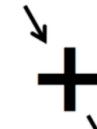

Time (2 x 5 min/run)

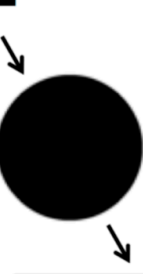




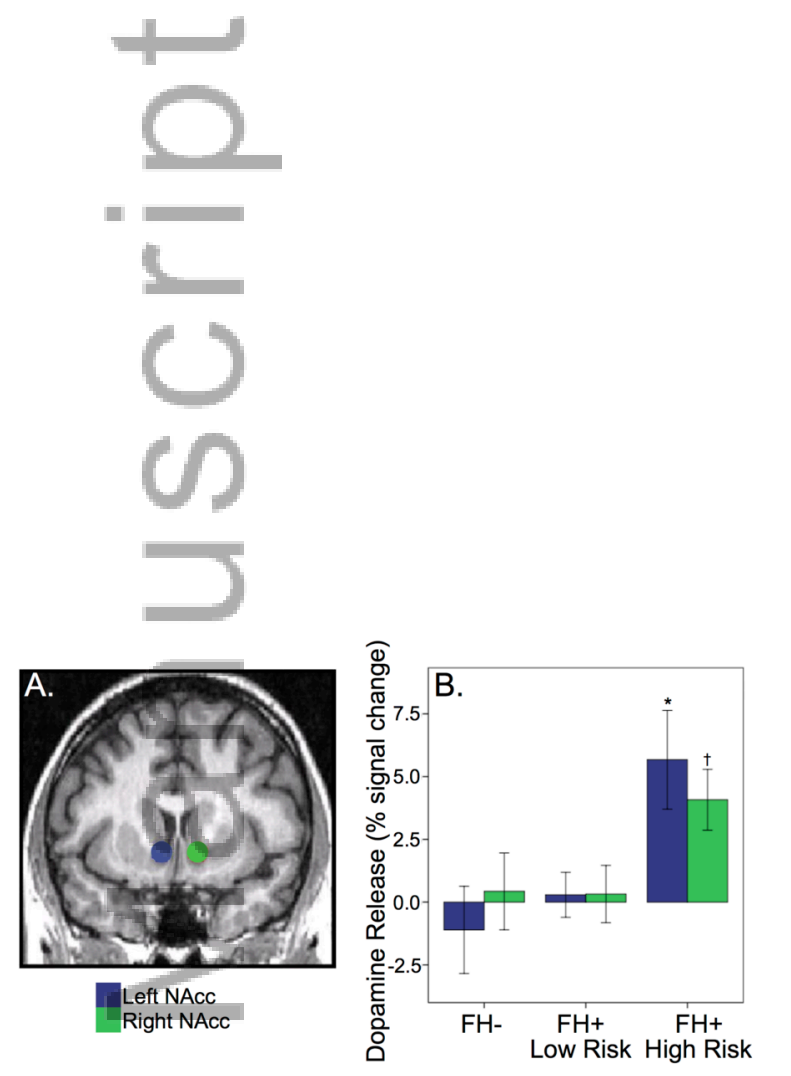

Figure 2
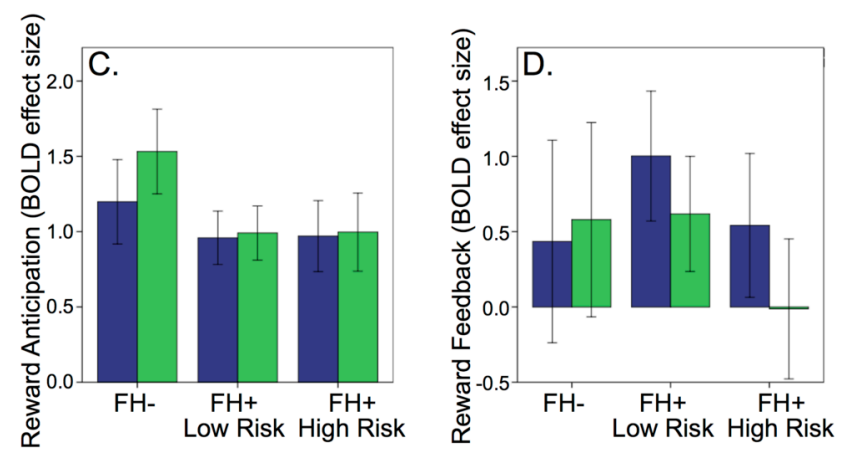

ADB_12341_F2.tiff

This article is protected by copyright. All rights reserved. 

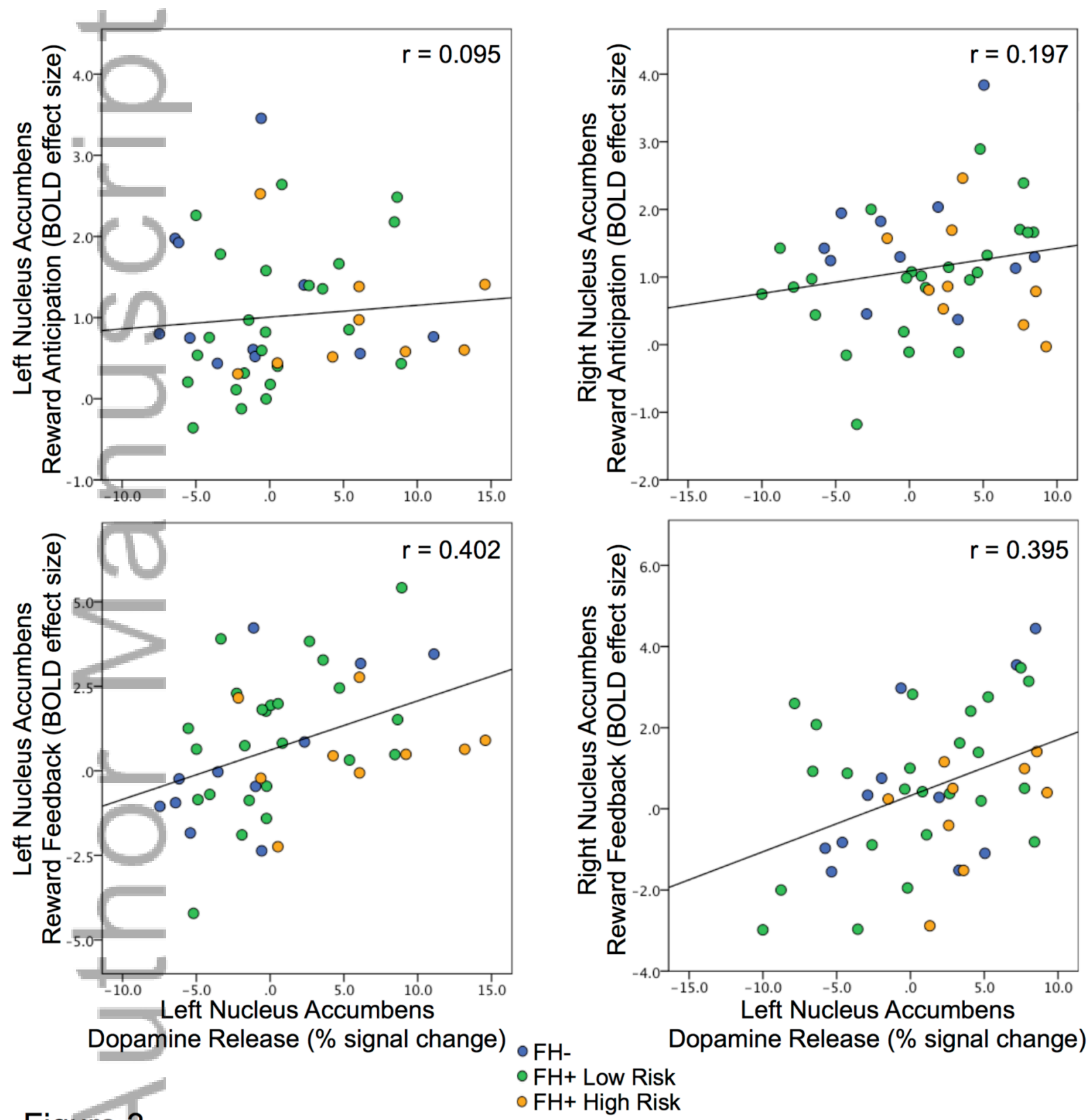

Figure 3

$\mathrm{FH}+$ Low Risk

ADB_12341_F3.tiff

This article is protected by copyright. All rights reserved. 


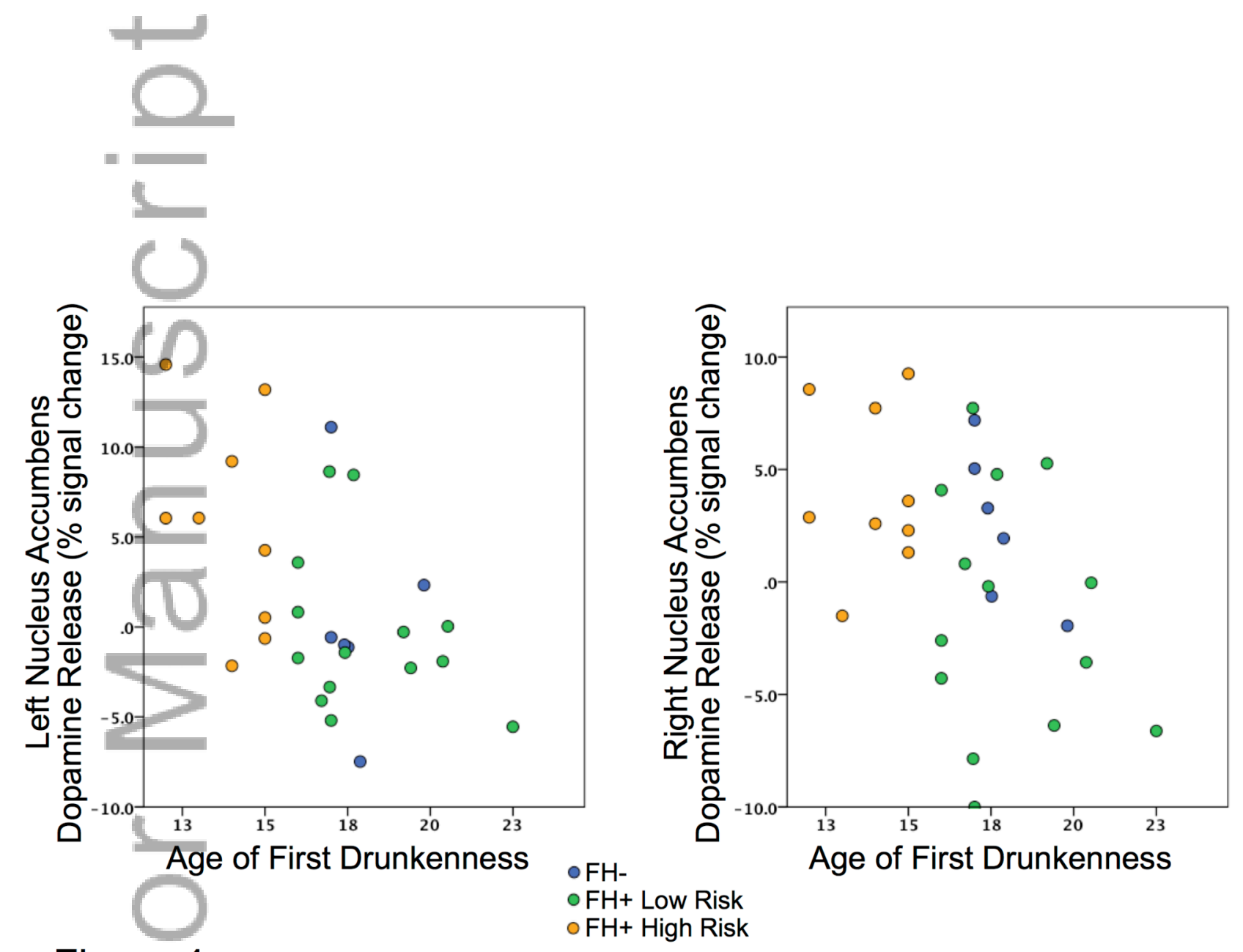

Figure 4

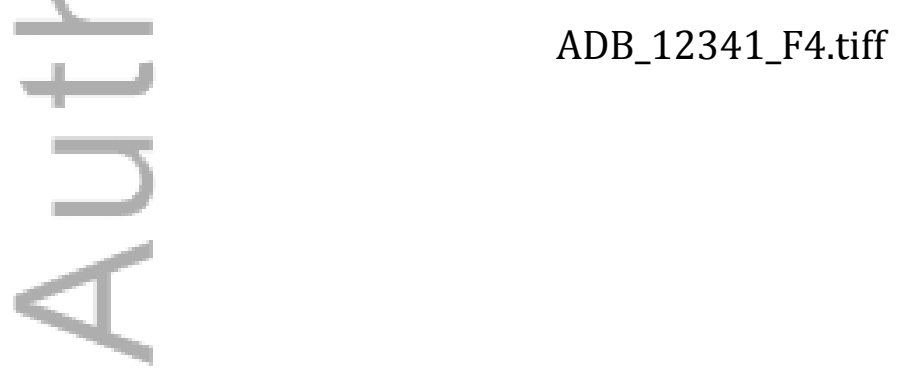

This article is protected by copyright. All rights reserved. 